\title{
J(৫)
}

\section{ÇAKMAK, S. (2019). Edîb Ahmed Yüknekî: Atebetü'l- Hakâyık, Inceleme-Tenkitli Metin-Tıpkıbasım, Türkiye Yazma Eserler Kurumu Başkanlığı Yayınları, Ankara, 2019, sS. 468, ISBN: 978-975-17-4150-9}

\author{
Şe nol KoRKMAZ \\ İstanbul/Turkey \\ E-mail: senolkorkmaz78@gmail.com
}

Atebetü'l-Hakâyık, Karahanlılar devrinde XII. yüzyılın ilk yarısında Edîb Ahmed Yüknekî tarafından yazılmış bir nasihat kitabıdır. Eser, Karahanlı beylerinden Muhammed Dâd Sipehsâlâr Bey'e sunulmuştur. Eser dörtlükler şeklinde ve aruz ölçüsü ile yazılmıştır. Eser, bir ahlak ve öğüt kitabı olduğu için eserde hikmet üslubu kullanılmıştır. Eserde başlıca şu konular işlenmiştir: Bilgi, dil, dünyanın dönekliği, cömertlik ve hasislik, tevazu ve kibir, harislik, kerem, hilm (yumuşak huyluluk, sakinlik) ve zamanenin bozukluğu.

Edîb Ahmed Yüknekî, eserinin değerini arttırmak için yer yer Kur'an'dan ayetler ve hadislerden örnekler kullanmıştır. Eser, Karahanlı Türkçesinin Kaşgar şivesi ile yazılmıştır ve Karahanlı döneminden kalan önemli dil yadigârlarından biridir. Eserin adı günümüz Türkçesine ‘Gerçeklerin Eşiği' olarak aktarılabilir. 


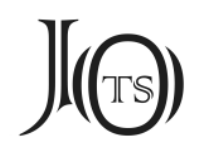

Atebetü'l-Hakâyık üzerine yapılan ilk neşir, 1918 yllında Necîb Âsım'ın Hibetü'l-Hakâyık isimli eseridir. Eserin en yetkin ve bilimsel neşri ise 1951 yllında Reşit Rahmeti ARAT tarafından Atebetü'l-Hakâyık adıyla yapılmıştır. Bu tarihten sonra eserle ilgili 2019 yılında iki yeni neşir çıkmıştır. Biri Sodık Kosımcon'un Özbekistan'daki neşri, diğeri de burada tanıtacağımız Serkan ÇAKMAK tarafından yapilan neşirdir.

ÇAKMAK'in eseri, önsöz, transkripsiyon alfabesi, inceleme, tenkitli metin, Necîb Âsım ve Hibetü'l-Hakâyık Neşri, Kaynakça, Resimler, Haritalar ve tıpkıbasım bölümlerinden oluşmaktadır. Eserin ana bölümleri ise şunlardır: inceleme, Tenkitli metin, Necîb Âsım ve Hibetü'l-Hakâyık Neşri.

Çalışmanın Önsöz (s. 9-11) bölümünde eserin tarihî önemi belirtildikten sonra eserin yedinci bir nüshasının bulunduğu belirtilmiştir (Hollanda nüshası). Çalışmada yapılacak incelemelerin yeni nüshasının ışı̆̆ında tekrar değerlendirildiği belirtildikten sonra Hollanda nüshası ile Necîb Âsım ve Hibetü'l-Hakâyık neşri hakkında bilgiler verilmiştir. Önsöz, kitabın yayınlanmasında emeği geçen kişiler, editör ve kitabın yayınlanmasına katkıda bulunanlara teşekkür edilerek bitirilmiştir.

Kısaltmalar (s. 13) bölümünün ardından çalışmada kullanılan transkripsiyon alfabesi (s. 15) verilmiştir.

İnceleme (s. 17-66) bölümünde 11 alt başlıkta yeni bulunan Hollanda nüshasının tanıtımı yapılmıştır. Eserin Adı kısmında eserden ilk kez ad vermeden Nevâyînnin bahsettiği belirtilmiştir. Nevâyî, Nesâyimü'l-Mahabbe ve Münşeât adlı eserlerinde eserden bazı dizeler almıştır. Eser üzerine ilk neşri yapan Necîb ÂsıM, Ayasofya nüshasını kullandığı için eserin adını Hibetü'l-Hakâyık olarak belirtmiştir. Kilisli Rıfat, yeni bulduğu Semerkand nüshasına dayanarak eserin adını Atebedü'l-Hakâyık Kitâbı olarak belirtir. Necîb ÂsIM ve Fuat KöPRÜLÜ ise eserin adını Aybetü'l-Hakâyık olarak değerlendirmişlerdir. Jean DENY, 1925 yılında Necîb Âsım'ın Semerkand nüshası hakkındaki makaleyi görmüş ve eserin adının Atebetü'l-Hakâyık olduğunu belirtmiştir. Eseri 1951 yılında yayımlayan Reşit Rahmeti ARAT ise Atebetü'l-Hakâyık adının orijinal, diğer adların ise müstensihlerce yapı- 


\section{J(৫)}

lan yanlış yazımlar olduğunu belirtmiştir. Hollanda nüshasında ise ad sadece başlıkta Aybetü'l-Hakâyık olarak geçmektedir. Yazar, daha sonra konuyla ilgili verileri özetlemiş ve ad konusunda en makul değerlendirmelerin Ahmet CAFEROĞLU tarafından yapıldığını belirtmiştir (s. 19).

Eserin Müellifi (s. 20-23) kısmında eserin yazarının adının açıkça Edîb Ahmed olduğu belirtilmiş, esere Arslan Hoca Tarhan'ın yazdığı ekte ise memleketi Yüknek olduğu söylenmiştir. Yazar, burada geçen Yüknek'in neresi olduğuna dair bilgileri vermiştir. Bu bölgenin Kaşgar, Semerkand, Maveraünnehir de olabileceğine dair görüşler belirtildikten sonra Selçuk UYSAL'in 2007'de yazmış olduğu bir makalede buranın Kazakistan'ın Türkistan şehrinin kuzey batısında yer alan Jüynek adlı köy olduğu belirtilmiştir.

Eserin İthaf Edildiği Kişi (s. 23-24) kısmında bu kişinin Dâd İspehsâlâr Bey olduğu söylenmiştir. Bu kişi eserde bir kez geçmekte olup Edîb Ahmed Yüknekî, ondan bahsederken şahım olarak söz etmiştir. Bu kısımda bu kişinin kim olabileceğine dair Necîb Âsım ve Fuat KöPRÜLÜ’nün görüşleri aktarılmıştır.

Eserin Başllk ve Bölümleri (s. 24-26) kısmında eserin on dört bâbdan oluştuğu belirtilmiştir. Bâblar ve ayet, hadis gibi alıntılar Arapça yazılmıştır. ARAT’a göre eserini Türkçe yazan ve dönemi için gayet anlaşllır bir dil kullanan müellifin, eserin başlıklarını Arapça yazması makul sayılamaz.

Eserin Vezin, Şekil ve Muhtevası (s. 26-28) kısmında eserin Şehnâme ve Kutadgu Bilig'in de yazıldığı aruzun mütekârib bahrinden alınan faûlün faûlün faûlün faûl ile yazıldı̆̆ı belirtilmiştir. Eserde iki nazım birimi kullanılmıştır. Eserin on beyitlik "tahmîd” (Allah'a övgü), ardından beş beyitlik "naat” (Peygamberi övme), beş beyitlik "Dört sahabenin Övgüsü”, on dört beyitlik Emîr Dâd İspehsâlâr Bey'in methiyesi ile altı beyitten oluşan sebeb-i telif bölümleri beyit nazım birimi ile yazılmıştır. Eserin asıl kısmı ise dörtlükler hâlinde yazılmıştır. Eserin tamamı 40 beyit ve 101 dörtlükten oluşmaktadır. Beyitle yazılan kısımlarda kafiye düzeni aa, $b b, c c$, vb., dörtlüklerle yazılan kısımda aaxa şeklindedir.

Eserin muhtevası ise çalışmada şu şekilde gösterilmiştir:

a. Bilginin yararı ve bilgisizliğin zararı hakkında (12 dörtlük) 


\section{J(G)}

b. Dilin muhafazası hakkında (12 dörtlük)

c. Dünyanın dönekliği hakkında (12 dörtlük)

d. Cömertliğin methi, hasisliğin zemmi hakkında (10 dörtlük)

e. Tevazu ve kibir hakkında (7 dörtlük)

f. Harislik (hırslı olma) hakkında (6 dörtlük)

g. Kerem, hilm ve diğer iyilikler hakkında (16 dörtlük)

h. Zamanenin bozukluğu hakkında (21 dörtlük)

1. Kitap sahibinin özrü hakkında (5 dörtlük)

Eserin Nüshaları (s. 28-34) kısmında eserin nüshaları tanıtılmıştır, buna göre eserin nüshaları şunlardır:

1. Semerkand Nüshası (Ayasofya 4012): Bu nüsha 1444 yılında Zeynelâbidîn adlı bir hattat tarafından Semerkand'da Uygur harfleri ile yazılmıştır, diğer nüshalara göre en sağlam ve eksiksiz olan nüshadır. 123 sayfadan oluşmaktadır ve her sayfada 6 satır vardır.

2. Ayasofya Nüshası: Eserin ilk bulunan ve neşri yapılan nüshasıdır. Toplam 174 yaprak olan mecmuanın 1b-27a arasında Atebetü'l-Hakâyık metni vardır. Bu nüshadaki metin Uygur harfli yazının altına Arap harfleriyle de yazılmıştır.

3. Topkapı Nüshası: Bu nüsha, Topkapı Sarayı Müzesi kütüphanesi Hazine bölümünde 244 numarada kayıtlı bir mecmuanın içindedir. Eser, Arap harfleriyle harekeli olarak yazılmıştır.

4. Uzunköprü Nüshası: Bu nüsha bugün kaybolmuştur. Nüsha hakkında Fuat KöPRÜLÜ ve Hüseyin Namık ORKUN'un verdiği bilgiler vardır. Nüshada Atebetüll-Hakâyık metni 11 varaktır. Bu nüsha baştan, sondan ve ortadan eksiktir. Toplam 234 dizeden oluşmaktadır.

\section{Eserden Dizelerin Yer Aldığı Bazı Nüshalar:}

a. Ankara'da bir mecmua içinde yer alan Atebetü'l-Hakâyık dizeleri, bu mecmua ile birlikte Fuat KöPRÜıÜ tarafından ilim âlemine tanıtılmıştır. 


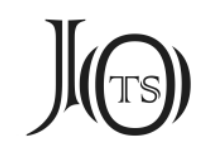

b. Berlin'de Prusya İlimler Akademisinin Türkçe Uygur metinleri arasında T. I. TM 287 işaretini taşıyan bir varak üzerinde Atebetü'l-Hakâyık'tan alınan bir dörtlük yazılıdır.

c. Ali Şîr Nevâyînnin Nesâyimü'l-Mahabbe min Şemâyimi'l-Fütüvve ve Münsşeât adlı eserlerinde de Atebetü'l-Hakâyık'tan alınan dörtlük ve beyitler bulunur.

6. Hollanda Nüshası: Bu nüsha, ayrı bir başlık altında incelenmiştir.

Eserin Dili (s. 35-36) kısmında yazar, Atebetü'l-Hakâyık'ın dilinin Karahanlı Türkçesi ve onun Kaşgar şivesi olduğunu belirtmiş ve konuyla ilgili çeşitli bilim adamlarının değerlendirmelerine yer vermiştir.

Aybetü'l-Hakâyık (Hollanda Nüshası) (s. 37-64) bölümünde Hollanda nüshası ile ilgili geniş bilgiler verilmekte ve nüshanın tanıtımı yapılmaktadır. Bilgiler şu başlıklar altında verilmiştir: Yaprak ve Cilt Özellikleri; İstinsah Tarihi, Yeri ve Müstensihi; Kütüphanedeki Geçmişi; Sayfa ve Hat Özellikleri; Mecmuadaki Diğer Metinler; Mecmuanın Tanıtıldığı Kataloglar; Aybetü'l-Hakâyık'ın Metni Hakkında: Genel Özellikleri, Yazım Özellikleri.

Hollanda nüshası, mevcut yazmanın 9a-32b varakları arasındadır. Hollanda'da Gronigen Üniversitesi kütüphanesinde muhafaza edilmektedir. Kütüphanede HS 474 kayıt numarasıyla saklanan bir mecmuanın içindedir. İstinsah tarihi olarak 1396 1397 tarihlerinin olabileceğine ihtimal verilmiştir. Metnin tamamı 404 dizedir ( $=32$ beyit +85 dörtlük). Eserin genel özellikleri kısmında yazmanın nüshası geniş ve ayrıntılı olarak tanıtılmış, yazım özellikleri kısmında ünlü ve ünsüzlerin yazımı açıklanarak ve örnek verilerek gösterilmiştir. Bu bölümün son kısmında Hollanda nüshasında bulunan bazı ayırıcı dil özellikleri hakkında bilgi verilmiştir. Bu bölüm, "Tenkitli Metin Kurulurken Takip Edilen Yöntem" kısmıyla bitirilmiş ve bu kısımda 6 madde verilmiştir.

Nüshalar için şu kısaltmalar kullanılmıştır:

$\mathrm{S}=$ Semerkand nüshas 1

A = Ayasofya nüshası

$\mathrm{T}=$ Topkapı nüshas 1 


\section{J(G)}

$\mathrm{M}=$ Maarif Kütüphanesi nüshası

$\mathrm{B}=$ Berlin Prusya İlimler Akademisi nüshası

Hollanda nüshası karşılaştırmada ana nüsha olduğu için onun için bir k1saltma kullanılmamıştır.

Çalışmanın Tenkitli Metin (s. 67-108) bölümünde Hollanda nüshası esas alınmış ve diğer nüshalarla karşılaştırılmıştır. Burada oluşturulan tenkitli metin, eserin doğru metnine ulaşmak için değil, Hollanda nüshasını gün yüzüne çıkarmak ve diğer nüshalarla farkını belirtmek için yapılmıştır. Eserde nüsha farklılıklarını göstermek için toplam 1042 aparat kullanılmıştır.

Çalışmanın üçüncü ana bölümüne Necîb Âsım'ın Hibetü'l-Hakâyık neşri eklenmiştir (s. 113-222). Yazar, Necîb Âsım'ın hayatı, Türkçülüğü ve eserleri hakkında bilgi verdikten sonra eserin Latinize edilirken izlenen yöntem anlaılmıştır (s. 125). Necîb Âsım, Hibetü'l-Hakâyık kitabının başında eser hakkında bilgiler vermiş, daha sonra eserde kullanılan alfabeyi belirtikten sonra Hibetü'l-Hakâyı'ın Ayasofya nüshası üzerinden Osmanlı Türkçesine trankripsiyonunu ve aktarımını (dil içi çeviri) yapmıştır. Yazar, eseri baştan sona beyitler şeklinde ele almıştır. Bunu yaparken beyitler altında bazı kelimelerle ilgili açılamalar bulunur (s. 142207). Yazar, eserin sonunda bir Zeyil eklemiş ve burada bazı dilbilgisi açıklamaları yapmıştır (s. 209-215). Çalışmanın sonunda bir Lugatçe eklenmiş, burada ele alınan kelimelerin karşılarına anlamları verilmiştir (s. 217-222).

Kaynakça (s. 223-226) bölümünde çalışmada kullanılan kaynaklar APA sistemine kullanılarak belirtilmiştir. Çalışmada toplam 52 kaynak adı gösterilmiştir.

Resimler (s. 227-228) bölümünde Atebetü'l-Hakâyık ile ilgili sekiz resmin görseli yer almaktadır. Haritalar (s. 229) kısmında ise X ve XI. yüzyıl Türk halklarını yerleşimi ile ilgili iki harita verilmiştir.

Çalışmanın dördüncü ve son ana bölümü ise Tıpkıbasım bölümüdür (s. 231468). Bu bölümde Atebetü'l-Hakâyık'ın en önemli dört nüshasının renkli ve son derece kaliteli tıpkıbasımı yapılmıştır. Tıpkıbasım bölümündeki nüshalar şunlardir:

1. Hollanda Nüshası: Gronigen Üniversitesi Kütüphanesi, HS 474 


\section{J(৫)}

2. Semerkand Nüshası (Ayasofya 4012): Süleymaniye Yazma Eserler Kütüphanesi, Ayasofya 4012

3. Ayasofya Nüshası: Süleymaniye Yazma Eserler Kütüphanesi, Ayasofya 4757

4. Topkapı Nüshası: Topkapı Sarayı Müzesi Kütüphanesi, Hazine 244

Atebetü'l-Hakâyık'ın ÇAKMAK tarafından yapılan neşri Türkiye Yazma Eserler Kurumu Başkanlığı Yayınları tarafından kurumun standart basım ölçülerine göre yapılmıştır. Çalışmanın ön kapağının kenarları siyah çerçeve içine alınmıştır. Ön kapakta lacivert bir zemin üzerinde beyaz harflerle üstte Atebetüll-Hakâyık, altta ise Edîb Ahmed Yüknekî adı yazılıdır. Bu yazıların altında ayna görünümlü renkli bir desen içinde eserin Uygur ve Arap harfli Ayasofya nüshasından bir sayfa örneği konmuştur. Arka kapakta ise lacivert zemin üzerinde önce Arap harfleri, sonra Latin harfleriyle 'Atabat al-Hakāyılk, Adīb Aḥmed Yuknaki yazılmıştır. Eser adı üstte, yazar adı altta yer almaktadır. Eserde kullanılan kâğıt, kaliteli ve tıpkıbasım için oldukça uygun olan bir kâğıt türüdür.

Karahanlılar döneminden kalan ve XII. yüzyıla ait önemli bir dil ve edebiyat yadigârı olan Atebetü'l-Hakâyık, bulunuşunun 100. yılında ÇAKMAK tarafından yeni bir nüshası keşfedilerek (Hollanda nüshası) tekrar neşredilmiştir. Çalışma, Türk dili, edebiyatı ve kültürünü anlamak için yapılan çalışmalara yeni bir katkı sağlamıştır. Necîb ÂsıM'ın Hibetü'l-Hakâyık neşrinin Latin harflerine aktarılarak esere eklenmesi ise çalışmaya çok büyük bir değer katmıştır. 


\section{)(요)}

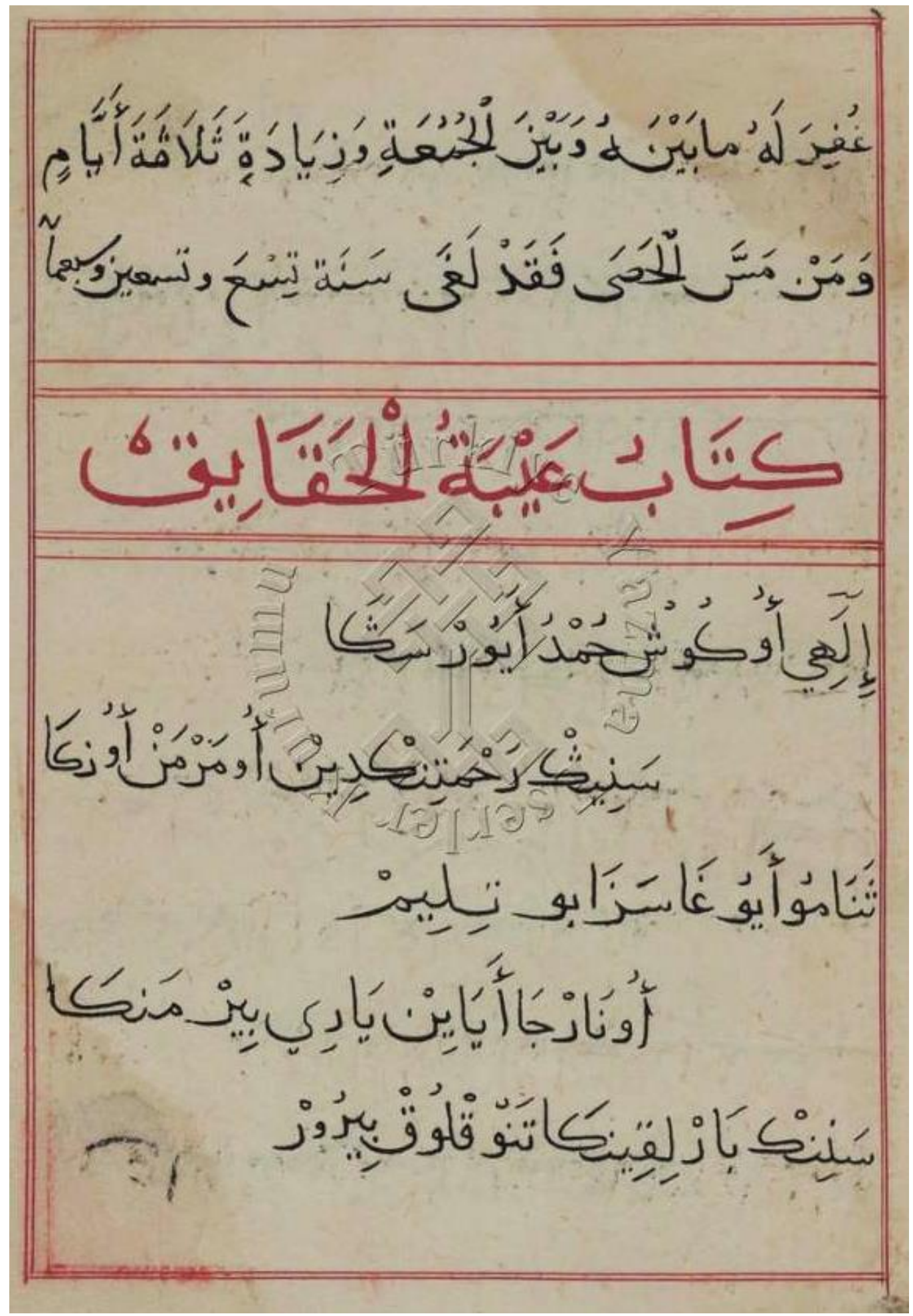

Hollanda Nüshasının ilk sayfası 